\title{
Electrophysiological Effects of Procaine in Rabbit Sino-Atrial Node Cells
}

\author{
Hiroyasu SATOH and Keitaro HASHIMOTO \\ Department of Pharmacology, Yamanashi Medical College, \\ Nakakoma-gun, Tamaho, Yamanashi 409-38, Japan
}

Accepted September 20, 1985

\begin{abstract}
Effects of procaine $(50-500 \mu \mathrm{g} / \mathrm{ml})$ on membrane potential and currents were investigated using a two microelectrode-voltage clamp technique. Procaine reduced the action potential amplitude (APA), the maximum diastolic potential and the maximum rate of depolarization $\left(\dot{V}_{\max }\right)$ in a dose-dependent manner. At the same time, the action potential duration and the cycle length were prolonged. In voltage clamp experiments, procaine $(50 \mu \mathrm{g} / \mathrm{ml})$ did not affect the slow inward current $\left(I_{\mathrm{si}}\right)$, but reduced the time-dependent outward current $\left(I_{\mathrm{k}}\right)$. At concentrations higher than $100 \mu \mathrm{g} / \mathrm{ml}$, procaine reduced both currents and the inward current activated by hyperpolarization in a dose-dependent manner. In 7 of 20 specimens, a low concentration of procaine $\left(50\right.$ or $100 \mu \mathrm{g} / \mathrm{ml}$ ) increased $\mathrm{I}_{\mathrm{si}}$ which enhanced the $\dot{V}_{\max }$ and APA, but did not increase $I_{k}$. Procaine did not affect the steady-state inactivation of $I_{s i}\left(f_{\infty}\right)$ and the activation of $I_{k}\left(p_{\infty}\right)$. The results suggest that the depressions of currents induced by procaine are due to a reduction in conductances of the current systems.
\end{abstract}

Local anesthetics have been reported to block the fast sodium current in Purkinje fibers and to shorten the action potential (1). The shortening has been explained by an increase in the outward current (2-4). From a theoretical point of view, the shortening of the action potential duration can also be explained by a reduction in inward current. During the plateau, inward and outward currents are practically in balance (5) and a small change in one of the currents will greatly affect the course of the potential. Recently, Carmeliet and Saikawa (6) and Colatsky (7), however, found that the shortening of action potential duration in sheep cardiac Purkinje fibers by local anesthetics (lidocaine, quinidine and procainamide) was not due to an increase in outward current, but could be explained by a block of an inward current through the TTX-sensitive channel. Vassalle and Bhattacharyya (8) also showed that procaine markedly shortened the action potential in Purkinje fibers, by an inhibition of the fast sodium current.
Thus, the mechanism of action of local anesthetics in Purkinje fibers has become clear, but yet not totally elucidated. As for other cardiac tissues such as the sino-atrial (SA) node cell, very little is known about the action of procaine, especially about its positive chronotropic effect. Senami and Irisawa (9) demonstrated a depressive action of procainamide (not procaine) on the activity of heart muscle cells. We studied the effects of local anesthetics on the canine SA node by means of selective perfusion with blood or Tyrode solution through the sinus node artery (10-12). Local anesthetics decreased the sinus rate and increased the action potential duration in a dose-dependent manner. However, a low concentration of procaine and prilocaine often increased the sinus rate following the initial negative chronotropic effect. It was quite different from lidocaine which only had the negative chronotropic effect. It is concluded that the positive chronotropic effect was due to a catecholamine up-take blocking action in the post-ganglionic adrenergic nerve ending, by 
means of procedures which included prior administrations of a beta blocker and TTX and administration of reserpine in living dogs.

In the present study, we wanted to elucidate the mechanism underlying the reduction or the acceleration of rabbit pacemaker activity and the prolongation of SA node action potential during exposure to procaine by means of the voltage clamp technique, as little information is available concerning the effect of procaine on slow inward and outward current systems and pacemaker current of SA node.

\section{Materials and Methods}

Preparations of sino-atrial node cells: Rabbits of either sex and $1.5-2.0 \mathrm{~kg}$ in weight were killed by a blow to the neck and exsanguinated. The methods have been described in detail in recent papers $(13,14)$. In brief, the chest was opened and the heart was quickly removed, and the right atrium with the SA node region left intact was dissected in Tyrode solution. The SA node was identified by its anatomical location. A small SA node specimen cut perpendicular to the crista terminalis was prepared. The specimen was made even smaller by dissections, and the final dimensions were about $0.25 \times 0.25 \mathrm{~mm}$. The small specimens, superfused at a rate of $3 \mathrm{ml} / \mathrm{min}$ with Tyrode solution, beat spontaneously. The temperature in the recording chamber was kept at $36 \pm 1{ }^{\circ} \mathrm{C}$.

Recording of the membrane potential and membrane currents: A two microelectrode voltage clamp technique (13-15) was used. Conventional glass microelectrodes were filled with $3 \mathrm{M} \mathrm{KCl}$ and its resistance was 20 30 Mohms. The membrane potential was held at $-40 \mathrm{mV}$ by using a feedback amplifier (MEC ME-3321). Test pulses were supplied from the holding potential to levels spaced $10 \mathrm{mV}$ apart. The interval between test pulses was more than $1 \mathrm{~min}$. When the membrane potential was not clamped, the preparations invariably showed spontaneous rhythmicity. The data were recorded on a storage oscilloscope (Nihon Kohden VC-10) and a pen recorder (Nihon Kohden RJG4124). The amplitude of $I_{s}$ was determined by measuring at $100 \mathrm{msec}$ after the onset of the step, as the method developed by McDonald and Trautwein (16). The magnitudes of $I_{k}$ and $I_{h}$ were measured by taking the difference between the value of the current at the end of a long clamp pulse and the steady value between test pulses. The tail current was measured as the difference between its peak amplitude and the steady value between test pulses.

Solutions: The composition of the modified Tyrode solution used (mM) was $\mathrm{NaCl}$, 134; $\mathrm{KCl}, 2.7 ; \mathrm{CaCl}_{2}, 1.8 ; \mathrm{MgCl}_{2}, 0.5$; and HEPES, 5.0, with $\mathrm{pH}$ adjusted to 7.4. Procaine hydrochloride (Daiichi Pharmaceutical Co., Ltd.) was dissolved with Tyrode solution to the desired concentration. Since the Tyrode solution in the bath was completely exchanged with solutions having different concentrations of procaine in at least $3 \mathrm{~min}$, the data were obtained $10 \mathrm{~min}$ after switching to the new solution.

Statistical analysis: The values were expressed as mean values \pm S.E. Student's $t$-test was used for the purpose of statistical analysis, and a $\mathrm{P}<0.05$ was considered significant.

\section{Results}

Effect of procaine on action potential of SA node cells: At concentrations of 10 and $30 \mu \mathrm{g} / \mathrm{ml}$, procaine induced no significant changes in the action potential of SA node cells, so effects of procaine at 50 to $500 \mu \mathrm{g} /$ $\mathrm{ml}$ are indicated in Fig. 1. Procaine at $50 \mu \mathrm{g} /$ $\mathrm{ml}$ slightly prolonged the cycle length (CL) and the action potential duration (APD) and reduced the maximum diastolic potential $\left(D P_{\max }\right)$. With $100 \mu \mathrm{g} / \mathrm{ml}$, the action potential amplitude (APA), DP $\max$ and the maximum rate of depolarization $\left(\dot{\mathrm{V}}_{\max }\right)$ were reduced by $9 \%, 23 \%$ and $38 \%$, respectively, and APD measured at $50 \%$ of repolarization was prolonged by $33 \%$. The rate of phase 4 depolarization was decreased, and $C L$ was increased by $25 \%$. Compared to lidocaine, procaine had less effect on APA, $\dot{V}_{\max }$ and $\mathrm{CL}$ and had a greater effect on APD and DP $\max$ (14). In quiescent SA node cells, the resting membrane potential was depolarized by about $10 \mathrm{mV}$ at $100 \mu \mathrm{g} / \mathrm{ml}$ of procaine. The shift behaved in a dose-dependent manner. The effects of procaine on various electrophysiological parameters of SA node potential are 


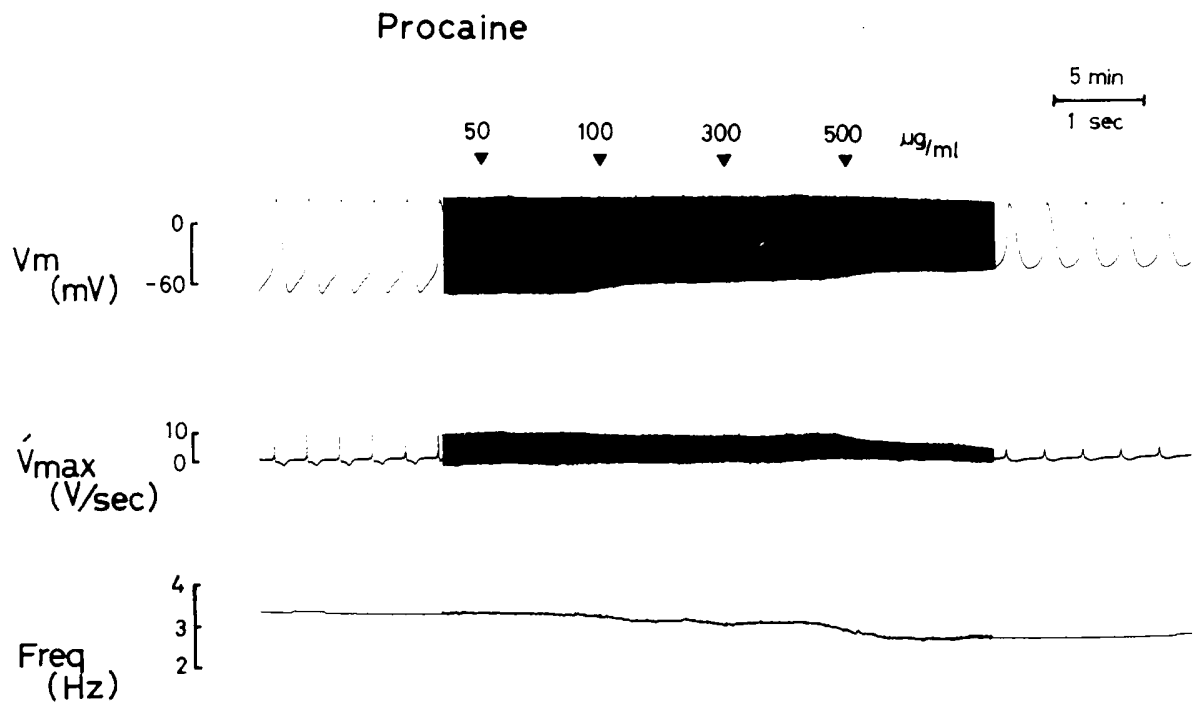

Fig. 1. Effect of procaine on rabbit SA node cells. Amplitude, $\dot{V}_{\max }$ and sinus rate were reduced in a dose-dependent fashion. At the same time, maximum diastolic potential decreased markedly.

summarized in Fig. 2. In 7 of 20 specimens, however, APA and $\dot{\mathrm{V}}_{\max }$ were increased during exposure to 50 or $100 \mu \mathrm{g} / \mathrm{ml}$ of procaine as shown in Fig. 3, even though $\mathrm{DP}_{\max }$ was slightly decreased. At higher concentrations, cessation of spontaneous activity occurred, although it resumes once the procaine administration was discontinued. The sinus arrest occurred in 2 of 17 specimens with 300 $\mu \mathrm{g} / \mathrm{ml}$ and in 3 of 17 specimens with 500 $\mu \mathrm{g} / \mathrm{ml}$. No sinus arrest occurred at the lower concentrations. The incidence of sinus arrest was lower than that induced by lidocaine (see 14).

Effect of procaine on the membrane currents of SA node cells: To examine the effect of procaine on the membrane currents, voltage clamp experiments were performed $(n=8)$. With concentrations higher than $100 \mu \mathrm{g} / \mathrm{ml}$, procaine reduced the inward current $\left(I_{\mathrm{si}}\right)$ in a dose-dependent manner. As shown in Fig. 4, however, lower concentrations of procaine $(50$ or $100 \mathrm{\mu g} /$ $\mathrm{ml}$ ) enhanced $\mathrm{I}_{\mathrm{si}}$, in 7 specimens. The membrane potential was held at $-40 \mathrm{mV}$. Procaine at $100 \mu \mathrm{g} / \mathrm{ml}$ increased $\mathrm{I}_{\mathrm{si}}$ by $17 \%$ at $0 \mathrm{mV}$. However, at doses higher than $300 \mu \mathrm{g} / \mathrm{ml}$, procaine did not increase $\left.\right|_{\mathrm{si}}$. The graph shows the current-voltage relationship in the absence (open circles) and in the presence of procaine $(50 \mu \mathrm{g} / \mathrm{ml}=$ triangles, $100 \mu \mathrm{g} / \mathrm{ml}=$ squares, $500 \mu \mathrm{g} /$ $\mathrm{ml}=$ filled circles) and that the $\mathrm{I}-\mathrm{V}$ curves are shifted in the inward direction with 50 and $100 \mu \mathrm{g} / \mathrm{ml}$ of procaine and in the outward direction with $500 \mu \mathrm{g} / \mathrm{ml}$.

The decay of $I_{s i}$ was measured for the initial $10 \mathrm{msec}$ in the absence and the presence of 100 and $500 \mu \mathrm{g} / \mathrm{ml}$ of procaine. and these data are plotted in Fig. 5 (symbols used are the same as in Fig. 4). The graph shows that the early decay of $I_{\mathrm{si}}$ was fitted by a single exponential line. The time constant was not altered, even though the instantaneous value was enhanced or depressed in the presence of procaine.

The inactivation curves of $l_{s i}$ in the absence and the presence of various concentrations of procaine are shown in Fig. 6. The protocol involved conditioning clamps from the holding potential of $-40 \mathrm{mV}$ to various values $(-60$ to $-10 \mathrm{mV})$. The test clamp was applied from the various levels of the conditioning clamp to $0 \mathrm{mV}$. On the left side in Fig. 6, the conditioning potential is to $-30 \mathrm{mV}$ and the test clamp to $0 \mathrm{mV}$. The $\mathrm{I}_{\mathrm{si}}$ flowing during the test clamp increased progressively with 50 or $100 \mu \mathrm{g} / \mathrm{ml}$, but with $500 \mu \mathrm{g} / \mathrm{ml}, I_{\mathrm{si}}$ decreased. In the graph, the abscissa shows the conditioning clamp level and the ordinate, 


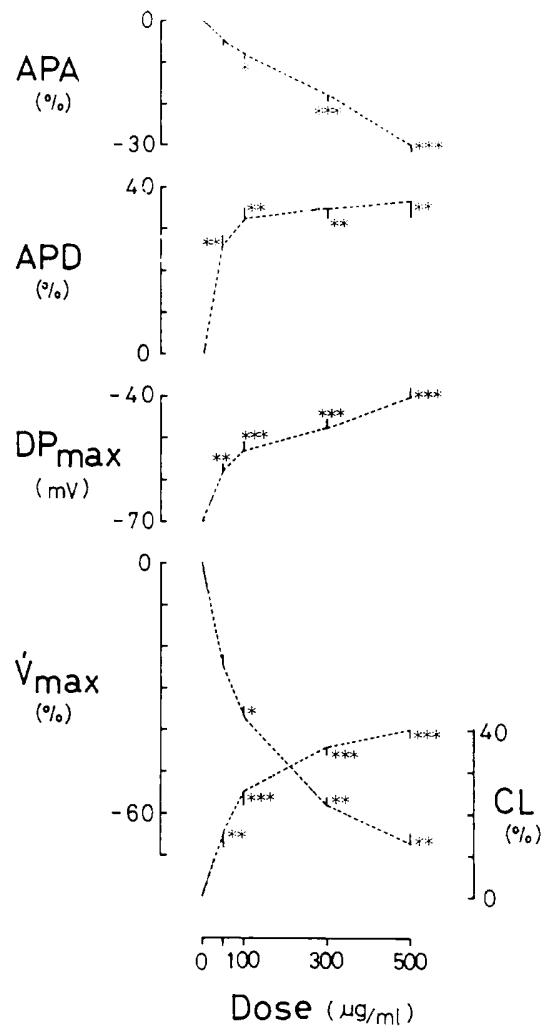

Fig. 2. Concentration-related changes in the parameters of the action potential induced by procaine. With an increase in concentration of procaine, the action potential amplitude (APA), the maximum diastolic potential (DPmax), the maximum rate of depolarization ( $\dot{\mathrm{V}}_{\max }$ ) were reduced, whereas the action potential duration (APD) and the cycle length $(C L)$ were prolonged. The control values of these parameters were: APA, $94 \pm 3 \mathrm{mV}$; APD, $75 \pm 4 \mathrm{msec}$; $\dot{\mathrm{V}}_{\max }, 11 \pm 2 \mathrm{~V} / \mathrm{sec}$; and $\mathrm{CL}, 293 \pm 7$ msec $(n=8)$. The values in some specimens that procaine produced the excitative effects on the action potentials were not included. Vertical bars represent the S.E.M. ${ }^{*} P<0.05,{ }^{* *} P<0.01,{ }^{* *} P<$ 0.001 , with respect to control values.

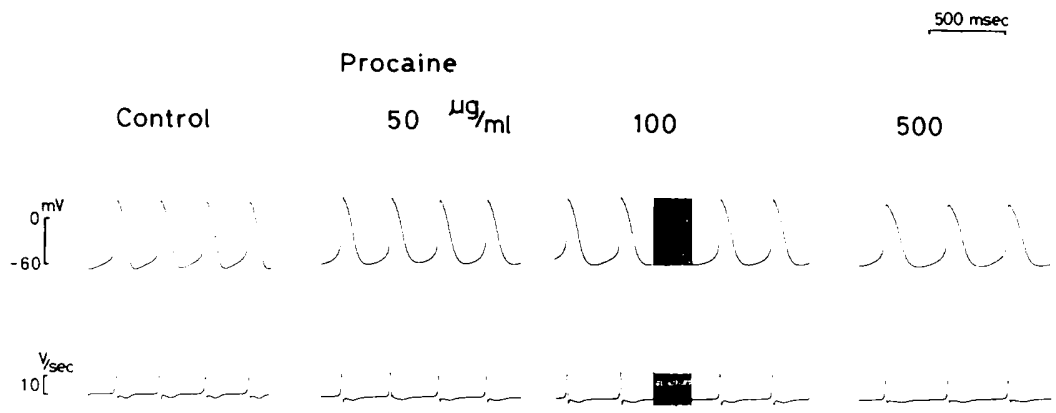

Fig. 3. Enhancement of spontaneous activity of SA node during exposure to the lower concentrations of procaine. The dose of 50 or $100 \mu \mathrm{g} / \mathrm{ml}$ enhanced $\dot{\mathrm{V}}_{\max }$, and it had a little or no effect on the cycle length. However, at $500 \mu \mathrm{g} / \mathrm{ml}, \dot{\mathrm{V}}_{\max }$ was greatly reduced, and APD and $\mathrm{CL}$ were increased.

the magnitude of $\mathrm{I}_{\mathrm{si}}$ during the test clamp. Although not shown in the figure, the curves in the right side of Fig. 6 could be normalized by taking the amount of slow inward current at $-40 \mathrm{mV}$ as $1.0\left(f_{\infty}\right)$. Normalized curves did not show any shift along the voltage axis.

Figure 7 shows a series of voltage clamp records and the current-voltage relationship for the steady-state currents in normal Tyrode solution and in the presence of various concentrations of procaine. The membrane potential was held at $-40 \mathrm{mV}$ and depolarizing or hyperpolarizing step pulses of $1 \mathrm{sec}$ duration were applied at increments of $10 \mathrm{mV}$. In this experiment, the specimen was different from that in Fig. 4 (in which $\mathrm{I}_{\mathrm{si}}$ 


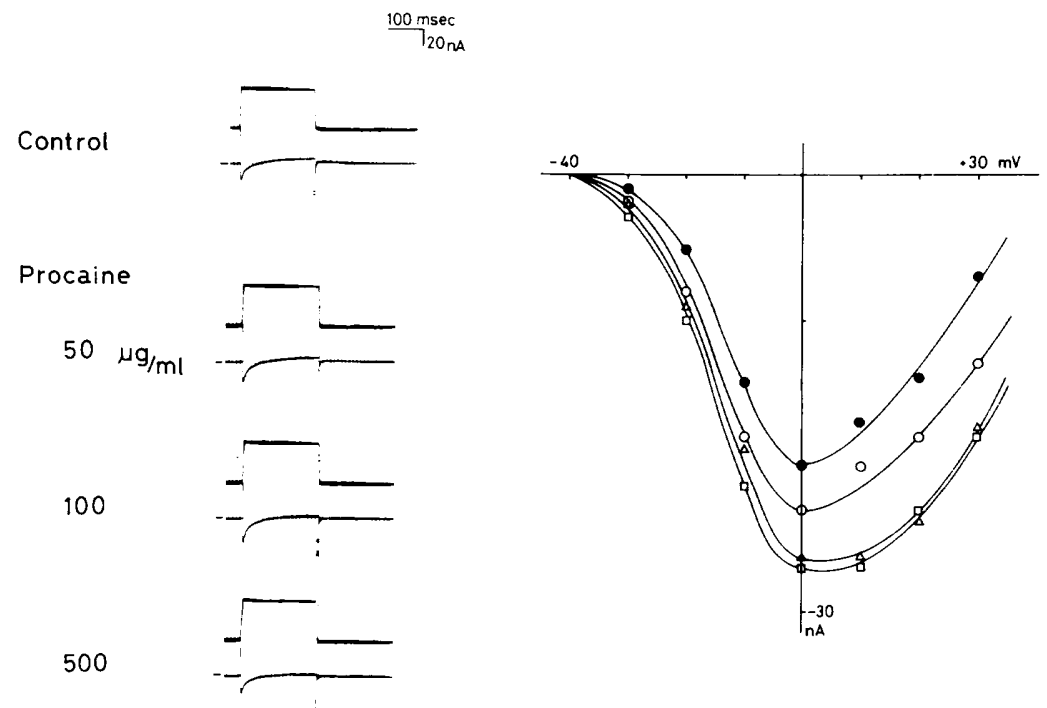

Fig. 4. Voltage-dependence of the procaine-induced changes in the slow inward current. Left panel: current record for test pulses from -40 to $0 \mathrm{mV}$. At 50 and $100 \mu \mathrm{g} / \mathrm{ml}$, procaine increased the slow inward current, but at $500 \mu \mathrm{g} / \mathrm{ml}$, it reduced it. A brief line before the record of membrane current indicates the zero current. The holding current was shifted by about $7 \mathrm{nA}$ at $500 \mu \mathrm{g} / \mathrm{ml}$. Right panel: current-voltage relationship for the slow inward current without drug (open circles), after exposure to $50 \mu \mathrm{g} / \mathrm{ml}$ (triangles). $100 \mu \mathrm{g} / \mathrm{ml}$ (squares) and $500 \mu \mathrm{g} / \mathrm{ml}$ (filled circles) of procaine.

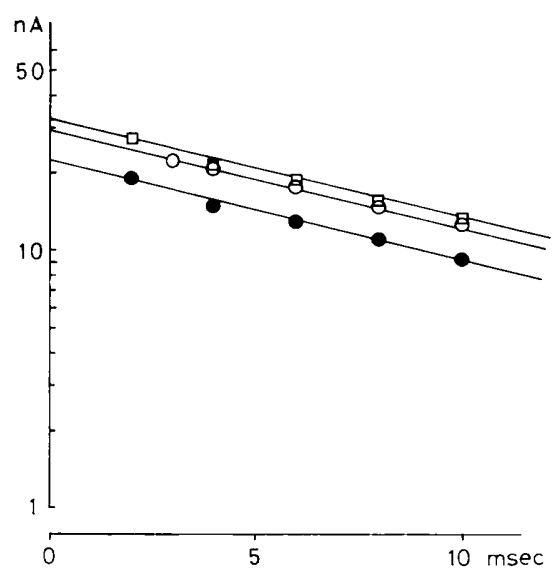

Fig. 5. The decaying time course of slow inward current in normal Tyrode (open circles), in $100 \mu \mathrm{g} /$ $\mathrm{ml}$ (squares) and in $500 \mu \mathrm{g} / \mathrm{ml}$ (filled circles) of procaine. Procaine did not affect the time constant of the inactivation process of $I_{s i}$, although it caused a depression or an enhancement in the peak value of Isi.

increased). In the presence of procaine, the holding current was shifted in the inward direction and more so, as the procaine con- centration became higher. However, even at $500 \mu \mathrm{g} / \mathrm{ml}$, the shift was less than $7 \mathrm{nA}$ (brief lines indicate zero current). Procaine decreased the steady-state outward current $\left(I_{k}\right)$ and the inward current activated by the hyperpolarizing pulse $\left(I_{h}\right)$. These changes were dose-dependent $(n=8)$. In the $\mid-V$ plot. the current values were measured after the clamp pulse at the end of $1 \mathrm{sec}$ as a function of the membrane potential. The I-V curve for $I_{k}$ in the presence of procaine was shifted in the inward direction and that for $I_{h}$ in the outward direction. Even in the 7 specimens which produced the increase in $I_{s i}$, procaine also reduced the steady-state currents $\left(I_{k}\right.$ and $I_{h}$ ) in a dose-dependent manner. These findings provide an explanation for the effect of procaine on the SA node action potential.

In order to examine the effect of procaine on the kinetic variable $(p)$ of $I_{k}$, the relationship between the peak of the outward current tail and the membrane potential during the test clamp was determined in the absence and the presence of procaine. In Fig. 8A, the magnitude of tail currents has been plotted along the membrane potential. 


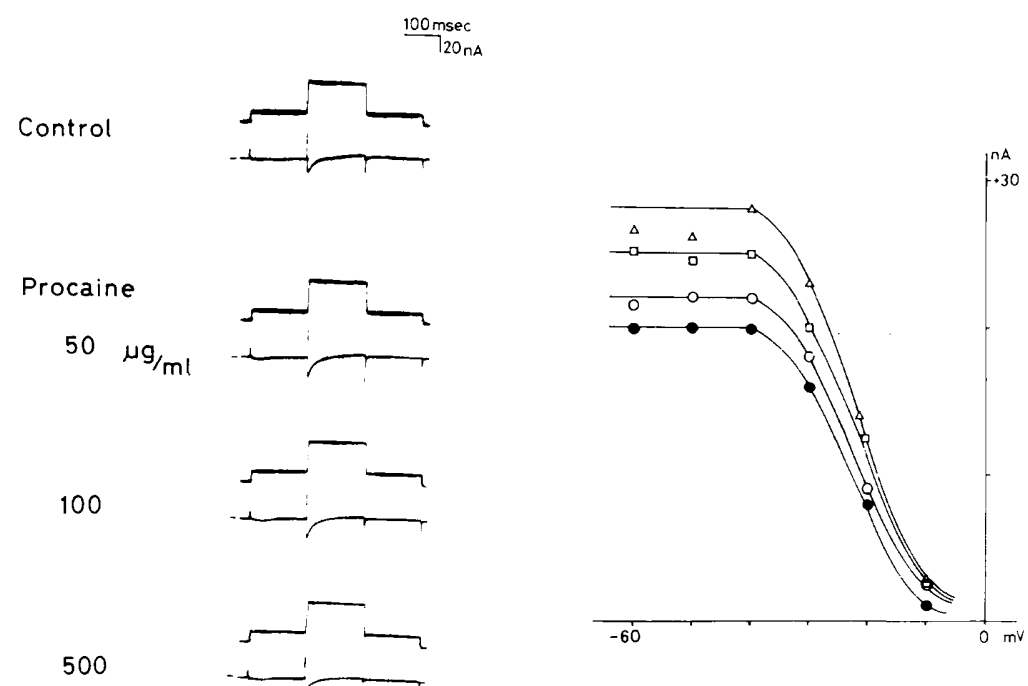

Fig. 6. Voltage-dependent inactivation curves for the slow inward currents before and during application of procaine. On the left: examples of voltage steps (from -40 to $-30 \mathrm{mV}$ and -30 to $0 \mathrm{mV}$ ) and membrane currents. The conditioning potential (first pulse) was changed from -60 to $-10 \mathrm{mV}$, and the test potential (second pulse) was always to $0 \mathrm{mV}$. A brief line before the record of membrane current represents the steady current value between voltage clamps (zero current). On the right: the amplitudes of slow inward current during the second pulse are plotted as a function of membrane potential. The symbols are similar to those in Figs. 4 and 5 . The curves can be fitted by a sigmoidal curve when normalized by taking the value at $-40 \mathrm{mV}$ as 1.0 . The sigmoidal curves were drawn visually.

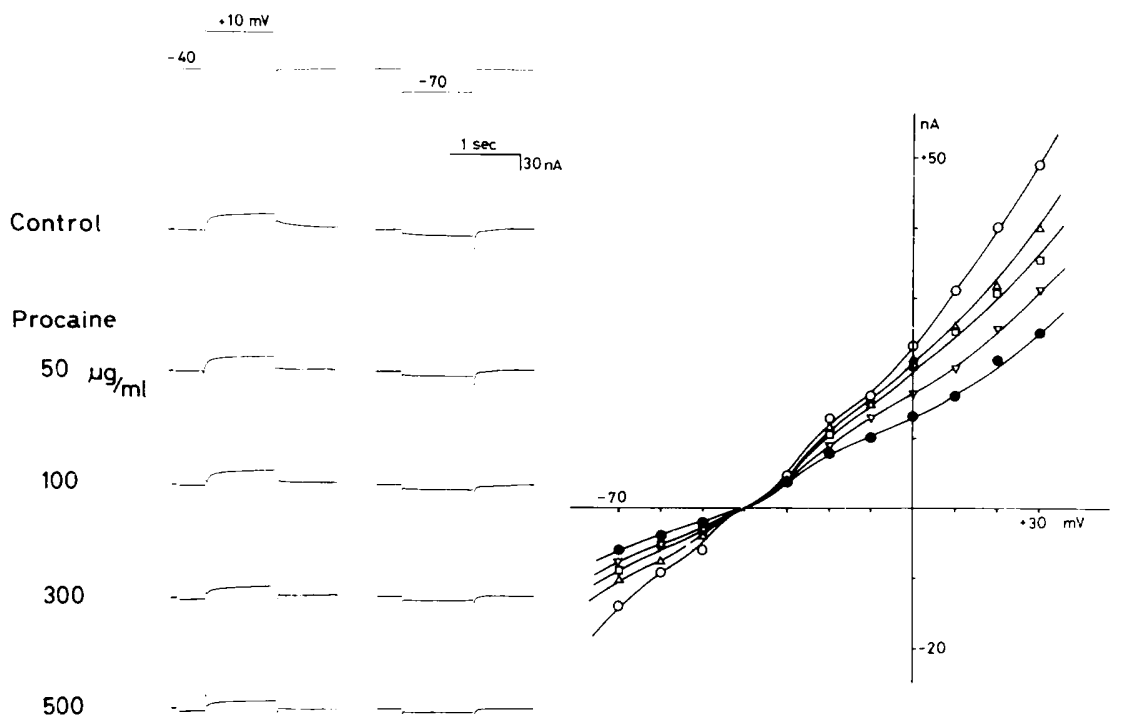

Fig. 7. Voltage-dependence of the procaine-induced decrease in steady-state currents. On the left: membrane currents during $1 \mathrm{sec}$ voltage pulses from -40 to $+10 \mathrm{mV}$ or -40 to $-70 \mathrm{mV}$ (SA node preparation is different from that in Figs. 4-6). On the right: the steady-state currents are plotted as a function of membrane potential. Symbols used in this figure are similar to those in Fig. 4, and reversed triangles indicate the response to $300 \mu \mathrm{g} / \mathrm{ml}$ of procaine. Even $50 \mu \mathrm{g} / \mathrm{ml}$ (triangles) of procaine caused distinct depressions in $l_{\mathrm{k}}$ and $\mathrm{l}_{\mathrm{h}}$. 


\section{A}

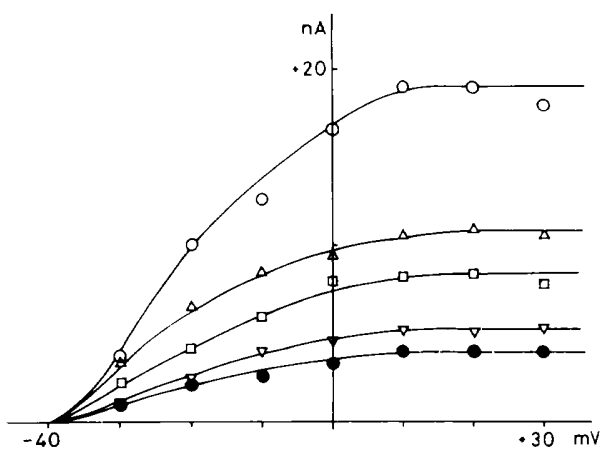

B

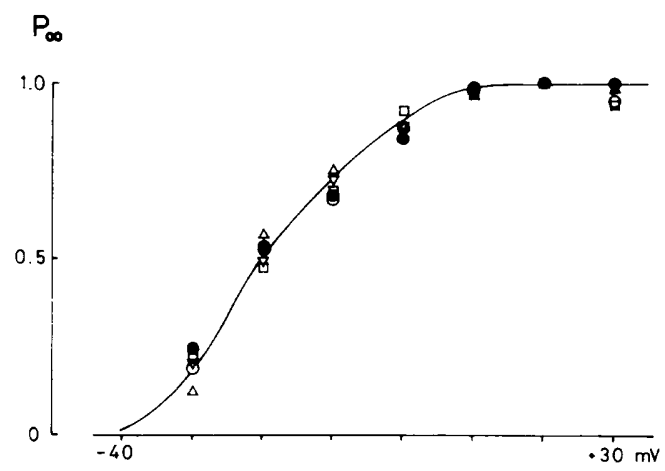

Fig. 8. Depression in the outward current tail in a dose-dependent manner without affecting its activation kinetic in the presence of procaine. A) Relationship between the peak outward current tail and the membrane potential during test pulses. The magnitude of the outward current tail was measured as the difference between the peak value and the steady value between clamps, and this was plotted. B) Normalized outward current tails (ordinate) were plotted as a function of the membrane potenital (abscissa). When all the data in A were normalized, the results could be expressed as a nearly single sigmoidal curve, and the half-maximum membrane potentials were approximately equal. This curve indicates the degree of the steady-state activation of $p$, which was unchanged in the absence and the presence of procaine. Symbols are similar to those in the previous figures.

Increasing concentrations of procaine caused a progressive reduction in the tail current amplitude. In Fig. 8B, the curves were normalized by taking the amplitude of the tail current at $+20 \mathrm{mV}$ as $1.0\left(p_{\infty}\right)$. This curve shows the degree of activation of the outward current as a function of the membrane potential. All the points in the Fig. 8B can be reasonably fitted by the same sigmoidal curve. which indicates that the half-maximum activation occurred at the nearly same potential both in the absence and the presence of procaine $(n=8)$, although procaine produced a decrease in amplitude of the outward current tail, as mentioned above.

\section{Discussion}

The present experiments show: (1) The SA node was resistant to procaine concentrations less than $50 \mu \mathrm{g} / \mathrm{ml}$. (2) At procaine concentrations higher than 50 or $100 \mu \mathrm{g} / \mathrm{ml}$, APA, $\dot{V}_{\max }$, and DP $\max$ were greatly decreased, and $A P D$ and $C L$ were markedly prolonged. (3) With concentrations higher than $50 \mathrm{\mu g} /$ $\mathrm{ml}$, procaine decreased $\mathrm{I}_{\mathrm{k}}$ and $\mathrm{I}_{\mathrm{h}}$ without affecting $p_{\infty}$. (4) With concentrations higher than $100 \mu \mathrm{g} / \mathrm{ml}$, procaine reduced $I_{s i}$ without affecting $f_{\infty}$ and the time course of inactivation. (5) In some specimens $(n=7)$, 50 and $100 \mu \mathrm{g} / \mathrm{ml}$ of procaine increased $\mathrm{I}_{\mathrm{s}_{1}}$, with no change in the kinetics. During the enhancement of $I_{\mathrm{s} 1}$, it did not increase $I_{\mathrm{k}}$.

It is concluded that the major factor responsible for the prolongation of action potential is the reduction in conductance of $I_{k}$, and that for the negative chronotropic effect is the decreases in $I_{s i}, I_{h}$ and $I_{k}$.

The effect of procaine on the action potential duration of SA node cells: The mode of action of local anesthetics certainly includes an impairment of the fast $\mathrm{Na}$ conductance which is activated during the upstroke $(1,17-19)$. By means of the voltage clamp, a block of the fast inward $\mathrm{Na}$ current was clearly demonstrated (20-22). Although the fast $\mathrm{Na}$ channel plays little or no role in the action potential of SA node cells, we have already reported that local anesthetics reduced the sinus rate and the atrial contraction of dog heart and prolonged its action potential duration $(10,12)$. Similar results are also obtained in the rabbit SA node cells (14). However, in cardiac Purkinje fiber, it has been described that local anesthetics produced a shortening of the action 
potential duration $(2,23)$ and that the shortening was due to an increase in $K$ conductance $(2,3)$. Vassalle and Bhattacharyya (8) suggested that the marked shortening of the action potential duration could be related to a curtailment of $\mathrm{Na}$ influx. Carmeliet and Saikawa (6) also indicated that local anesthetics caused a block of the fast current and thereby produced an apparent increase in the outward current. The information by Carmeliet and Saikawa (6) was confirmed by the fact that the shift of the steady-state outward current in the outward direction is slightly larger for TTX alone than for local anesthetics. Although local anesthetics and TTX interfere with the Na channel, the site of the block is not the same. Local anesthetics have to diffuse in the lipid phase of the membrane and reach the intracellular phase before they can interfere with the $\mathrm{Na}$ channel (21), whereas TTX acts from the outside (24).

The different effects of procaine on the action potential duration in different tissues could result from the mechanism of action of the drug and from the ionic characteristics of the tissues. Thus, procaine prolongs the action potential in the SA node cells (12). and shortens it in Purkinje fibers $(2,4,7)$. The reason for such a difference can be explained by the fact that the fast $\mathrm{Na}$ channel plays little or no role in the activation of the SA node cells (in contrast to Purkinje fibers), and therefore, a block of such a channel in SA node cells would have little effect on the action potential duration. From a theoretical point of view, the prolongation of SA node action potential may be due to a reduction of the outward current, an increase in slow inward current or an increase in inward leakage current. The present results favor the reduction of the outward current as the cause of the increase in action potential duration in SA node cells, because on one hand, procaine decreased markedly the outward current in a dose-dependent manner; and on the other hand, the current-voltage relationships for the slow inward current and for the hyperpolarization activated inward current were decreased, and the curves were not shifted along the voltage axis. Therefore, the procaine-induced action potential pro- longation and the reduction of the resting potential in quiescent SA node cells should be mainly due to the decrease in the outward current. These results are in agreement with that of Colatsky (7) in that a reduction of $I_{x}$ (equivalent to $I_{k}$ of $S A$ node cells) by quinidine may explain the small lengthening of the action potential of Purkinje fibers. It seems possible to explain the fact that the maximum diastolic potential decreased even when $I_{s i}$ was enhanced during exposure to the lower concentrations of procaine (Fig. $3)$. In comparison with lidocaine (see 14), the action potential of the SA node was significantly lengthened even by $50 \mu \mathrm{g} / \mathrm{ml}$ of procaine. Procaine had a greater effect on $A P D$ and $D P_{\max }$ than lidocaine.

The negative chronotropic effect of procaine: Procaine reduced the slow inward current, the outward current and the hyperpolarization activated inward current. These changes must have decreased the slope of the pacemaker depolarization. Yanagihara et al. (25) showed that the pacemaker depolarization in SA node cells is mainly due to a gradual increase in $I_{\mathrm{si}}$ during diastole and that the contribution of $\mathrm{I}_{\mathrm{k}}$ is much less compared to the potassium current $I_{k 2}\left(I_{f}\right)$ in Purkinje fiber pacemaker depolarization. At the same time, a change in $l_{h}$ during diastole is much smaller compared to those of $I_{\mathrm{si}}$ and $\mathrm{I}_{\mathrm{k}}$. On the other hand. Brown et al. (26) have proposed that the original $g_{k}$ decay hypothesis correct. Further, Shibata and Giles (27) have analyzed the ionic currents underlying pacemaker activity in isolated frog sinus venosus cells and their work not only shows that rhythmic activity occurs in single node cells but also that it conforms to the $g_{\mathrm{k}}$ decay hypothesis, with $I_{\mathrm{si}}$ playing a role towards the end of the pacemaker depolarization. In addition. Maylie et al. (28) demonstrated the importance of the onset of the pacemaker current $\left(I_{h}\right)$. Thus, the field is now somewhat confused. If the $\mathrm{I}_{\mathrm{si}}$ hypothesis is correct, it could be concluded that in SA node cells, the main cause of the negative chronotropic effect of procaine is due to a decrease in $\mathrm{I}_{\mathrm{si}}$. In the $\mathrm{g}_{\mathrm{k}}$ decay hypothesis, the mechanism is due to a change in the decay of $\mathrm{K}$ current transported by the delayed rectifier channels during 
diastole. In the $\mathrm{I}_{\mathrm{h}}$ hypothesis, it is due to a decrease in $\mathrm{I}_{\mathrm{h}}$. Anyhow, an interaction of $\mathrm{I}_{\mathrm{si}}, \mathrm{I}_{\mathrm{k}}$ and $\mathrm{I}_{\mathrm{h}}$ might contribute to SA node pacemaker activity, and procaine could cause the negative chronotropic effect by affecting these current systems. The prolongation of the action potential by procaine also should partly contribute to the decrease in the rate of the SA node $(12,29)$. Local anesthetics also have a negative chronotropic effect in Purkinje fibers, and this effect may be attributed to a reduction of the pacemaker current and an inhibition of the fast $\mathrm{Na}$ current (6).

The enhancement of the slow inward current induced by procaine: $\ln 7$ of 20 specimens, procaine produced the increase in $l_{\mathrm{si}}$. We have already demonstrated that in canine SA node perfused arterially by the blood, a biphasic response, initially negative and secondary positive chronotropism, was observed after an administration of a lower dose of procaine (11). The initial negative chronotropic effect was not affected by atropine, whereas the occurrence of the second stimulatory phase was inhibited by prior administration of propranolol or tetrodotoxin through the SA node artery or in the reserpine-treated dogs. These findings indicated that the biphasic response was induced by a direct negative chronotropic action of procaine in the SA node and was followed by an indirect effect mediated by an interaction with the post-ganglionic adrenergic nerves, as presumably an action of an up-take blocker like cocaine. This conclusion is consistent with that of Vassalle and Bhattacharyya (8). In the present experiments, on the premise that procaine possesses the action of an up-take blocker, we made an extended study. It seems impossible to perform the same procedures as mentioned above, for the specimens perfused arterially with blood showed the positive responses to procaine more frequently than with Tyrode solution. Although it is impossible to exactly explain this, it might require binding proteins in blood $(11,12)$. Furthermore, since we must use smaller specimens by dissections, it is much more difficult to maintain for a long time the activity of the SA node cells during repeated exposure to the depressive agents or under a circumstance with depleted catecholamine. In rabbit SA node cells, there was no change in the voltage-dependency of the inactivation of $I_{s i}$, although procaine increased or decreased the magnitude of $I_{\mathrm{s}}$. Reuter (30) shows that the steady-state kinetics of $f$ was not altered by betaadrenergic agonists. Therefore, the present experiments make it clear that in rabbit SA node cells, procaine at 50 and $100 \mu \mathrm{g} / \mathrm{ml}$ might act as an up-take blocker and enhance $I_{\mathrm{si}}$.

In the present experiments, procaine decreased $I_{\mathrm{si}}, I_{\mathrm{k}}$ and $I_{\mathrm{h}}$, but there was a great requirement for high concentrations, as it was required for lidocaine to be much higher than the therapeutic concentrations to decrease the currents. However, there were no pronounced changes in the values of steady-state activation of $I_{k}\left(p_{\infty}\right)$ and of the inactivation of $I_{s i}\left(f_{\infty}\right)$ in the presence of procaine. Therefore, the decrease in the outward current was most probably caused by a reduction of $\bar{I}_{\mathrm{k}}$. We concluded that procaine causes a lengthening of the action potential and a decrease in the resting potential by reducing $\bar{I}_{\mathrm{k}}$. In addition, procaine reduces the action potential amplitude, the maximum rate of depolarization and the pacemaker depolarization by reducing $\tilde{I}_{\mathrm{s} i}$, by which it decreases $I_{\mathrm{si}}$. In some preparations procaine increased $I_{\mathrm{si}}$ (lidocaine never increased it) and did not affect $f_{\infty}$ and the time constant of $I_{s i}$.

Acknowledgments: The authors thank Daiichi Pharmaceutical Co., Ltd., for the supply of procaine hydrochloride and would also like to thank Mr. J. Sendoda and Miss. M. Yamada for their help in preparing this munscript. This work was supported by a research grant from the Ministry of Education, Science and Culture of Japan.

\section{References}

1 Weidmann, S.: Effects of calcium ions and local anesthetics on electrical properties of Purkinje fibers. J. Physiol. (Lond.) 129, 568-582 (1955)

2 Bigger, J.T. and Mandel, W.J.: Effect of lidocaine on the electrophysiological properties of ventricular muscle and Purkinje fibers. J. Clin. Invest. 49, 63-77 (1970)

3 Arnsdorf, M.H. and Bigger, J.T.: Effect of lidocaine hydrochloride on membrane con- 
ductance in mammalian cardiac Purkinje fibers. J. Clin. Invest. 51, 2252-2263 (1972)

4 Weld, F.M. and Bigger, J.T.: The effect of lidocaine on diastolic transmembrane currents determining pacemaker depolarization on cardiac Purkinje fibers. Cir. Res. 38, 203-208 (1976)

5 McAllister, R.E., Noble, D. and Tsien, R.W.: Reconstruction of the electrical activity of cardiac Purkinje fibers. J. Physiol. (Lond.) 251. 1-59 (1975)

6 Carmeliet, E. and Saikawa, T.: Shortening of the action potential and reduction of pacemaker activity by lidocaine, quinidine and procainamide in sheep cardiac Purkinje fibers - An effect on $\mathrm{Na}$ or K currents? Cir. Res. 50, 257--272 (1982)

7 Colatsky, T.J.: Mechanisms of action of lidocaine and quinidine on action potential duration in rabbit cardiac Purkinje fibers. An effect on steady state sodium current? Cir. Res. $50,17-27$ (1982)

8 Vassalle, M. and Bhattacharyya, M.: Local anesthetics and the role of sodium in the force development by canine ventricular muscle and Purkinje fibers. Cir. Res. 47, 666-674 (1980)

9 Semani, M. and Irisawa, H.: Effect of procaine amide on the membrane currents of the sinoatrial node cells of rabbits. Japan. J. Physiol. 31. 225-236 (1981)

10 Satoh, H.: Comparison of the chronotropic responses to local anesthetics (Procaine. lidocaine, prilocaine, mepivacaine and bupivacaine) of the canine sinus node in situ. Japar. J. Pharmacol. 31, 85-93 (1981)

11 Satoh, H., Azumi, T., Yoshida, T. and Nakajima, T.: Negative and positive chronotropic effects of procaine on the canine SA node in situ. Arch. Int. Pharmacodyn. Ther. 241, 307-315 (1979)

12 Satoh, H., Nakajima, T., Hashimoto, K. and Imai, S.: Effects of lidocaine and procaine on the action potential of canine sinus nodal cells. Japan. Heart J. 22, 929-937 (1981)

13 Satoh, H. and Hashimoto, K.: Effect of propafenone on the membrane currents of rabbit sino-atrial node cells. Eur. J. Pharmacol. 99, 185-191 (1984)

14 Satoh, H. and Hashimoto, K.: Effect of lidocaine on membrane currents in rabbit sino-atrial node cells. Arch. Int. Pharmacodyn. Ther. 270, $241-$ 254 (1984)

15 Noma, A. and Irisawa, H.: A time- and voltagedependent potassium current in the rabbit sinoatrial node cell. Pflügers Arch. 372, 43-51 (1976)

16 McDonald, T.F. and Trautwein, W.: Membrane currents in cat myocardium-Separation of inward and outward components. J. Physiol. (Lond.) 274, 193-216 (1978)

17 Carmeliet, E. and Verdonck, F.: Effects of aprindine and lidocaine on transmembrane potentials and radioactive $K$ efflux in different cardiac tissues. Acta Cardiol. 29, 73-90 (1974)

18 Reiser, J., Freemen, A.R. and Greenspan, K.: Aprindine - A calcium-mediated antidysrhythmic. Fed. Proc. 33, 476 (1974)

19 Josephsor, I. and Sperelakis, N.: Local anesthetic blockade of $\mathrm{Ca}^{+}$-mediated action potentials in cardiac muscle. Eur. J. Pharmacol. 40, 201-208 (1979)

20 Taylor, R.E.: Effect of procaine on electrical properties of squid axon membrane. Am. J. Physiol. 196, 1071-1078 (1959)

21 Hille, B.: Local anesthetics-Hydrophy!ic and hydrophobic for the drug-receptor reaction. J. Gen. Physiol. 69, 497-515 (1977)

22 Payet, M.D.: Effect of lidocaine on fast and slow inactivation of sodium current in rat ventricular cells. J. Pharmacol. Exp. Ther. 233, 235-240 (1982)

23 Weld, F.M. and Bigger, J.T.: Effect of lidocaine on the early inward transient current in sheep cardiac Purkinje fibers. Circ. Res. 37, 630-639 (1975)

24 Narahashi, T., Anderson, N.C. and Moore, J.W.: Tetrodotoxin does not block excitation from inside the nerve membrane. Science 153, 765767 (1966)

25 Yanagihara, K., Noma, A. and Irisawa, H.: Reconstruction of sino-atrial node pacemaker potential based on the voltage clamp experiments. Japan. J. Physiol. 30, 841-857 (1980)

26 Brown, H.F., Kimura, J. and Noble, S.J.: The relative contribution of various time-dependent membrane currents to pace-maker activity in the sino-atrial node. In Cardiac Rate and Rhythm, Edited by Bouman. L.N. and Jongsma, H.J., p. 53-68, Martinus Nijhoff Medical Division, The Hague (1983)

27 Shibata, E.F. and Giles, W.R.: Ionic currents in isolated cardiac pace-maker cells from buffering sinus venosus. Proc. Int. Union Physiol. Sci. 15, 76 (1983)

28 Maylie, J., Morad, M. and Weiss, J.: A study of pace-maker potential in the rabbit sino-atrial node: measurement of potassium activity under voltage-clamp conditions. J. Physiol. (Lond.) 311, 161-178 (1981)

29 Lipsius, S.L. and Vassalle, M.: Characterization of a two-component upstroke in the sinus node subsidiary pacemakers. In The Sinus Node, Edited by Bonke, F.I.M., p. 233-244, Martinus 
Nijhoff Medical Division. The Hague (1979)

30 Reuter, H.: Effects of neurotransmitters on the slow inward current. In The Slow Inward Current and Cardiac Arrhythmias, Edited by Zipes, D.P.,
Bailey, J.C. and Elharrar, V., p. 205-219, Martinus Nijhoff Medical Division, The Hague (1983) 